\title{
Application of Latent Class Modelling in Students' Life Skills: The Case of Iran University of Medical Sciences
}

\author{
Tofigh Mobaderi ${ }^{1}$, Masoud Salehi ${ }^{1}$ and Masoud Roudbari (iD) ${ }^{1,{ }^{*}}$ \\ ${ }^{1}$ Department of Biostatistics, Iran University of Medical Sciences, Tehran, Iran \\ "Corresponding author: Department of Biostatistics, School of Public Health, Iran University of Medical Sciences, Hemmat Express Way, Tehran, Iran. Tel: +98-9123887600, \\ Email: roudbari.m@iums.ac.ir
}

Received 2019 March 11; Revised 2019 July 01; Accepted 2019 September 10.

\begin{abstract}
Background: Many people facing life difficulties are unable to sort out these problems.

Objectives: A study was designed to determine students' life skills at the Iran University of Medical Sciences (IUMS).

Methods: This cross-sectional study was conducted at IUMS in 2016 - 17 with a sample of 342 students. A questionnaire was used with multi-choice questions from poor to high skills. Latent class models were applied for data analysis using Mplus. Bayesian information criterion (BIC) and Bootstrap likelihood ratio tests were used to determine the number of classes.

Results: A two-class model had the best fit since the BIC had the lowest amount. Almost $76 \%$ and $24 \%$ of the cases entered the high and moderate skill classes of the model, respectively. The level of education (LOE) was the only significant variable $(\mathrm{P}=0.004)$ for classifying the students.

Conclusions: The model could predict the probability of high life skilled students. Also, LOE had a high impact on the probability of high life skills.
\end{abstract}

Keywords: Life Skills, Students, Latent Class, Iran University of Medical Sciences

\section{Background}

Life skills include some attitudes, behaviors, and abilities that help the person to overcome life problems for a successful life. The promotion in educational and occupational situations in early life is one of the consequences of these life skills (1). Learning the skills of coping, adaptability, and flexibility in early life can promote mental health. Social-emotional learning to manage stress and teaching life skills in Iranian schools can reduce the risk factors of behavioral and emotional problems later in life; thus, it has a positive effect on mental health (2). Therefore, having higher life skills enables one to control his interpersonal behaviors and have less social and mental stress (3).

Singh et al. believe that life skills are group competencies and skills that can help people to solve problems, think critically, communicate effectively, and build relationships (4). Sahebalzamani et al. believe that many psychological disorders are due to the disability of people in solving their personal problems, correct facing difficult conditions, and managing difficult life situations (5). Ndetei et al. mentioned in their study in Kenya that life skills for school children improved their physical and mental health status (6). Wingenbach introduced life skills as the skills that help the individual promote the level of relationship and decision-making power, make relationships, learn his understanding, and work with groups (7). Lolaty stated in her study that a transition from high school to university causes some stress for students. These stresses are due to the need for creating a relationship, learning new study habits, and being an independent individual (8).

\section{Objectives}

The study objective was to investigate the students' abilities in 10 subscales of life skills using latent class models, find the number of classes, and check the effect of demographic variables on these probabilities.

\section{Methods}

This cross-sectional study was conducted in Iran University of Medical Sciences (IUMS) faculties in 2017. The target population was IUMS students, 342 of whom were selected by the stratified sampling method. The following formula was used to calculate the sample size based on the sample required to estimate a population mean with an 
approximate 95\% confidence level and unknown standard deviation:

$n=\left(\frac{Z_{\frac{\alpha}{2}} \times \sigma}{d}\right)^{2}, \sigma=\frac{\max \left(\operatorname{mean}\left(x_{i}\right)\right)-\min \left(\operatorname{mean}\left(x_{i}\right)\right)}{6}$

Where the maximum and minimum mean scores of responses were 4 and 0 , respectively, $\sigma=(4-0) / 6=0.66$, and the degree of precision of 0.07 .

The questionnaire of the study consisted of demographic variables including age, gender, education level (B.Sc., M.Sc., MD, and Ph.D.), marital status, income level (less than 100,0000, 1,000,000 to 2,000,000, 2,000,000 to 3000,000 , more than $3,000,000$ Toman), and residence situation (university accommodation, other). The life skill questionnaire completed by the students had 78 questions in 10 subscales (Table 1 ).

The questionnaire had five-scale Likert questions, which were standardized in another study (3). In this questionnaire, "no skill" was shown by zero, "weak skill" by 1 , "relatively weak skill" by 2 , "relatively strong skill" by 3 , and "strong skill" by 4 . Therefore, the mean score of each question for each student is between zero and 4; the higher the mean score, the more the students' acquired life skills (3).

To prepare the data for latent class analysis, quantitative variables were changed to binary variables by dividing the mean scores of 10 subscale variables into two categories of $\geq 2$ (good life skills) and $<2$ (weak life skills).

We used the latent class analysis to determine the level of life skills and evaluate the effect of demographic predictors on these skills. This analysis is an advanced statistical method that builds a model for the relationship between observed categorical variables and a discrete latent variable. In this method, the sample units are divided into different classes according to their responses, so the units in each class have the same responses and those who are

\begin{tabular}{lcc}
\hline Table 1. Subscales of Life Skill Questionnaire & & \\
\hline Subscale & Number of Question & Question \\
\hline Decision-making & 8 & $1-8$ \\
\hline Problem-solving & 6 & $9-14$ \\
\hline Creative thinking & 6 & $15-20$ \\
\hline Critical thinking & 10 & $21-30$ \\
\hline Effective communication & 11 & $31-41$ \\
\hline Inter-personal relation & 4 & $42-45$ \\
\hline Self-consciousness & 15 & $46-60$ \\
\hline Empathy & 8 & $61-68$ \\
\hline Coping with emotions & 3 & $69-71$ \\
\hline Coping with stress & 7 & $72-78$ \\
\hline
\end{tabular}

not in the same classes have different responses. This property can let the researcher compare the classes according to the participants' responses $(9,10)$. In the latent class models, the effect of predictors on each class of participants can be modeled at the same time (11-13). In this study, the unconditional latent class model (ignoring the effects of predictors) and the conditional latent class model were fitted to the data. To find the best number of latent classes, we used different indices including Bayesian information criterion (BIC), Bootstrap likelihood ratio test (BLRT), LoMendell-Rubin likelihood ratio (LMRLR), and adjusted LoMendell-Rubin likelihood ratio (ALMRLR) $(14,15)$. The low value of BIC indicates a better fit and the significant tests of BLRT, LMRLR, and ALMRLR indicate that the model has a better fit than other models with different classes. The entropy index with the minimum value of 0.8 indicates that the quality of classes in the model is fine $(11,13)$. Also, we used logistic regression to review the effect of predictors on the classes. The data were analyzed using SPSS version 18 software and Mplus 6.12.

The study was confirmed by the Ethics Council of IUMS under the reference number of IR-IUMS REC 95-03-2729485.

\section{Results}

The recruited participants in this study included 126 (36.8\%) B.Sc. students, 92 (26.9\%) M.Sc. students, 96 (28.1\%) MD students, and 28 (8.2\%) Ph.D. students. The highest score of life skills belonged to Ph.D. students and the lowest one belonged to medical students. The highest score of life skills belonged to the participants from the school of Management $($ Mean $=220.3, S D=39.42)$ and Public Health (Mean $=214.3, \mathrm{SD}=34.08$ ) and the lowest belonged to the school of Medicine (Mean $=210.3, \mathrm{SD}=39.42)$ without any significant differences $(\mathrm{P}=0.313)$. The mean age of the participants was $23.7 \pm 4.49$ years, with a low, non-significant correlation between age and life skill score $(\mathrm{r}=0.04, \mathrm{P}=$ 0.548).

Also, 302 (88.3\%) students were single and 39 (11.4\%) were married; the life skill score of married participants (218.7) was non-significantly more than that of single participants (210). Female students had more life skill scores (Mean $=216.9, \mathrm{SD}=35.89)$ than male participants (Mean $=$ 208.1, SD =32.65), but the difference was not significant ( $P$ $=0.07$ ). The life skill score was lower in students living in the university accommodation than in others but without any significant difference.

To determine the level of life skills in participants, the mean scores of life skills were calculated (between 0 and 4) (Table 2). 


\begin{tabular}{lcc}
\hline Table 2. The Mean and Standard Deviation of Students' Life Skill Scores & \\
\hline Subscale & Mean & SD \\
\hline Decision-making & 2.7 & 0.57 \\
\hline Problem-solving & 2.5 & 0.62 \\
\hline Creative thinking & 2.8 & 0.65 \\
\hline Critical thinking & 2.8 & 0.51 \\
\hline Effective communication & 2.7 & 0.55 \\
\hline Interpersonal relationship & 2.8 & 0.64 \\
\hline Self-consciousness & 2.5 & 0.51 \\
\hline Empathy & 2.8 & 0.55 \\
\hline Coping with Emotions & 2.8 & 1.01 \\
\hline Coping with stress & 2.7 & 0.59 \\
\hline
\end{tabular}

Table 2 shows that the highest mean score was related to the interpersonal relationship subscale and the lowest mean score was related to the problem-solving subscale with the mean of 2.5. The mean scores of all subscales were greater than the average 2 .

Table 3 shows the frequency and percentage of life skill levels for each subscale. Table 3 also shows that a high percentage of participants were classified as high skill participants.

The presented results in Table 4 showed that BLRT, LMRLR, and ALMRLR tests were significant for models with 2, 3 , and 4 classes; therefore, these models had better fit than previous models. Among these models, the model with two classes had the lowest BIC index and considered the best fitting model.

The entropy value for the chosen model (with two classes) was 0.807 that revealed that the evaluated classification was fine. The probability of having high life skills was calculated for each subscale for the chosen model (Table 5). Table 5 shows that the first class included 260 sample units (76\%) with high life skills with a probability of more than 0.95 . Therefore, $76 \%$ of the sample units were included in the first class, which had high life skills with high probability. About 24\% of the sample units were included in the second class, which had a moderate probability to have high life skills. Also, according to the BIC index and tests, classes 4 and 5 did not enter the model.

We can infer according to Table 5 if a sample includes in class 2 , it has a probability of 0.835 to have high critical thinking and probability of 0.536 to have high problemsolving, and so on.

In the next stage to evaluate the effect of demographic factors such as age, gender, education level, marital status, income level, and accommodation status, the latent class conditional model was fitted to the data. Table 6 shows the

\begin{tabular}{|c|c|}
\hline Subscale, Levels of Skills & Frequency (\%) \\
\hline \multicolumn{2}{|l|}{ Decision-making } \\
\hline High & $311(91.2)$ \\
\hline Low & $30(8.8)$ \\
\hline \multicolumn{2}{|l|}{ Problem-solving } \\
\hline High & $293(86.4)$ \\
\hline Low & $46(13.6)$ \\
\hline \multicolumn{2}{|l|}{ Creative thinking } \\
\hline High & $319(94.1)$ \\
\hline Low & $20(5.9)$ \\
\hline \multicolumn{2}{|l|}{ Critical thinking } \\
\hline High & $325(95.3)$ \\
\hline Low & $16(4.7)$ \\
\hline \multicolumn{2}{|l|}{ Effective communication } \\
\hline High & $315(92.1)$ \\
\hline Low & $27(7.9)$ \\
\hline \multicolumn{2}{|c|}{ Interpersonal relationship } \\
\hline High & $319(93.5)$ \\
\hline Low & $22(6.5)$ \\
\hline \multicolumn{2}{|l|}{ Self-consciousness } \\
\hline High & $306(90)$ \\
\hline Low & $44(10)$ \\
\hline \multicolumn{2}{|l|}{ Empathy } \\
\hline High & $319(93.5)$ \\
\hline Low & $22(6.5)$ \\
\hline \multicolumn{2}{|l|}{ Coping with emotions } \\
\hline High & $300(88.2)$ \\
\hline Low & $40(11.8)$ \\
\hline \multicolumn{2}{|l|}{ Coping with stress } \\
\hline High & $296(86.8)$ \\
\hline Low & $45(13.2)$ \\
\hline
\end{tabular}

results of the conditional model.

The results of the conditional latent class presented in Table 6 were similar to the data of Table 5 with just one difference including 29 missed data; therefore, the interpretation of Table 6 is similar to Table 5 .

To evaluate the effect of covariates on the latent class, the logistic regression was fitted to the data. In this model, the class number (classes 1 or 2) was considered as the response variable and the demographic variables were entered into the model as predictors (Table 7). In this logistic regression model, class 1 was considered as the reference 


\begin{tabular}{|c|c|c|c|c|}
\hline Number of Classes & BIC & BLRT & LMRLR & ALMLR \\
\hline One classes & 2065.88 & N.P. & - & - \\
\hline Two classes & 1868.87 & $\mathrm{PV}<0.001$ & $\mathrm{PV}<0.001$ & $\mathrm{PV}<0.001$ \\
\hline Three classes & 1889.86 & $\mathrm{PV}<0.005$ & $\mathrm{PV}<0.034$ & $\mathrm{PV}<0.036$ \\
\hline Four classes & 1914.28 & $\mathrm{PV}<0.001$ & $\mathrm{PV}<0.010$ & $\mathrm{PV}<0.011$ \\
\hline Five classes & 1960.19 & $P V=0.485$ & $P V=0.342$ & $P V=0.348$ \\
\hline
\end{tabular}

Abbreviation: N.P., not possible to calculate.

\begin{tabular}{lcc}
\hline Table 5. The Probability of High Life Skills & \\
\hline Subscale & $\begin{array}{c}\text { The First Latent Class } \\
(\mathbf{N}=\mathbf{2 6 0}) \text { Had High } \\
\text { Life Skills with High } \\
\text { Probability }\end{array}$ & $\begin{array}{c}\text { The Second Latent } \\
\text { Class }(\mathbf{N}=\mathbf{8 2}) \text { Had } \\
\text { High Life Skills with } \\
\text { Moderate Probability }\end{array}$ \\
\hline Decision-making & 1.0 & 0.656 \\
\hline Problem-solving & 0.976 & 0.536 \\
\hline Creative thinking & 0.987 & 0.806 \\
\hline Critical thinking & 0.994 & 0.835 \\
\hline $\begin{array}{l}\text { Effective } \\
\text { communication }\end{array}$ & 0.996 & 0.703 \\
\hline $\begin{array}{l}\text { Interpersonal } \\
\text { relationship }\end{array}$ & 0.986 & 0.778 \\
\hline Self-consciousness & 0.991 & 0.635 \\
\hline Empathy & 0.975 & 0.819 \\
\hline $\begin{array}{l}\text { Coping with } \\
\text { emotions }\end{array}$ & 0.957 & 0.666 \\
\hline Coping with stress & 0.953 & 0.620 \\
\hline
\end{tabular}

group, so in the interpretation of the predictor variables, the odds of being in class 2 (versus class 1 ) were estimated. For example, in Table 7, the education level was significant and the odds ratio for this variable was equal to 1.77, which indicated that the odds of being in class 2 (versus class 1 ) increased by 1.77 with each unit increase in education level (while holding other variables fixed). The other predictor variables were not significant at the 0.05 significance level.

\section{Discussion}

According to the results, $36.8 \%$ of the students were undergraduates, $26.9 \%$ were in the master level, $28.1 \%$ were in medicine discipline, and $8.2 \%$ were Ph.D. students. Also, $88.3 \%$ of the participants were single and $11.5 \%$ were married. The life skill score was non-significantly higher in married participants than in single participants. It seems married students had more skills due to their ages, which were almost older than single students.

The highest score of life skills belonged to the interpersonal relationship subscale with the mean score of 2.8 out

\begin{tabular}{lcc}
\hline Table 6. Probability of Having High Probability in Conditional Model \\
\hline Subscale & $\begin{array}{c}\text { The First Latent Class } \\
(\mathbf{N}=\mathbf{2 3 1})^{\mathbf{a}} \text { Had High } \\
\text { Life Skills with High } \\
\text { Probability }\end{array}$ & $\begin{array}{c}\text { The Second Latent } \\
\text { Class }(\mathbf{N}=\mathbf{8 2}) \text { Had } \\
\text { High Life Skills with } \\
\text { Moderate Probability }\end{array}$ \\
\hline Decision-making & 0.999 & 0.699 \\
\hline Problem-solving & 0.982 & 0.568 \\
\hline Creative thinking & 0.995 & 0.809 \\
\hline Critical thinking & 0.994 & 0.835 \\
\hline $\begin{array}{l}\text { Effective } \\
\text { communication }\end{array}$ & 1.0 & 0.742 \\
\hline $\begin{array}{l}\text { Interpersonal } \\
\text { relation }\end{array}$ & 0.989 & 0.804 \\
\hline $\begin{array}{l}\text { Self-consciousness } \\
\text { Empathy }\end{array}$ & 0.994 & 0.642 \\
\hline $\begin{array}{l}\text { Coping with } \\
\text { emotions }\end{array}$ & 0.989 & 0.814 \\
\hline Coping with stress & 0.964 & 0.720 \\
\hline $\begin{array}{l}\text { a In some variables, there were missed data, so 29 sample units were deleted } \\
\text { from the model. }\end{array}$ & 0.958 & 0.623 \\
\hline
\end{tabular}

of 4 and the lowest was related to the problem-solving subscale with the mean score of 2.5; also, the level of life skills was between $86.8 \%$ and $95.3 \%$ for most subscales.

In most life skills, female students were more skilled than males and had better scores, but without any significant differences. Tuttle et al. (16) and Akhavan Rezayat et al. (3) showed in their research that there was a significant relationship between life skills and gender, which is in contrast to the results of this study.

According to different educational levels, the highest life skills belonged to Ph.D. students and the lowest one belonged to medical students, but without any significant differences. It seems that due to the long period of the study of medical students, especially in clinical courses, they are too busy with their courses, patients, etc., thus, their life skills are lower than the skills of others.

To assess life skills according to the faculties of participants, the highest score belonged to the schools of Management and Public Health and the lowest belonged to the 


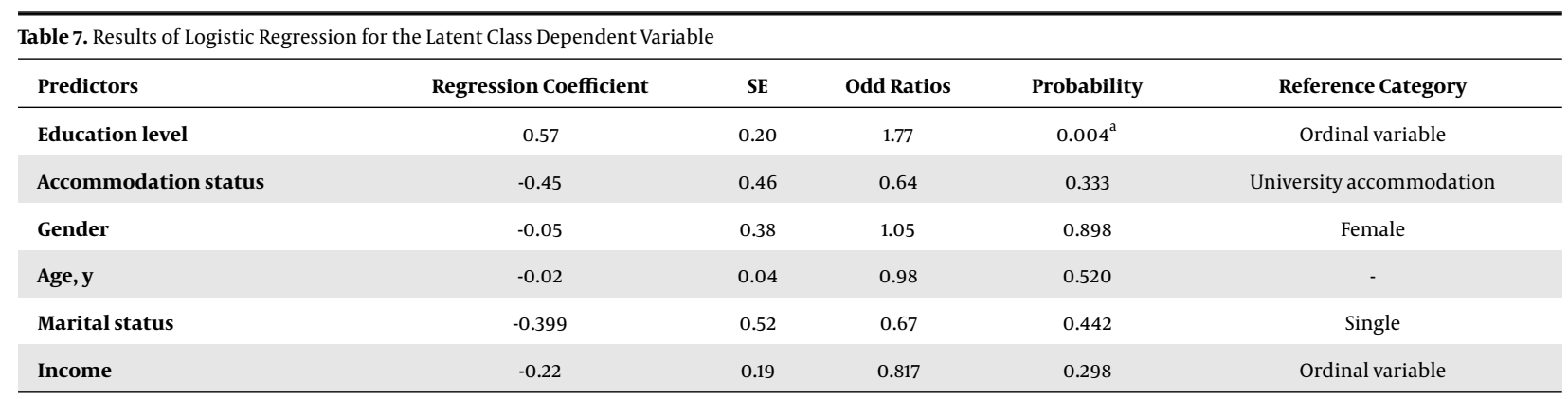

${ }^{\mathrm{a}}$ Significance at 0.05

school of Medicine, without any significant differences. It seems that medical students are very busy with their studies, especially clinical courses; thus, they have not enough time to learn life skills.

The life skills of students living in university accommodation were less than the life skills of others but without any significant differences. It seems that nonaccommodated students have more relationships with other students of different ages, ethnicity, etc., thus, their life skills are more than others.

There was a low, non-significant correlation between the age of the participants and the life skill scores, but a study proved that the last-year undergraduate students had more life skills than others (17).

Using BIC indices and tests, the latent model with two classes was chosen as the best model. In this model, latent class 1 included $76 \%$ of the sample units and this sample had high life skills with a probability of 0.95 . The frequency of the sample in latent class 2 was $24 \%$ and this sample had moderate life skills.

The probability of high life skills in latent class 1 for all subscales was more than 0.95 and at most, it was equal to one. The probability of high life skills in latent class 2 was between 0.536 and 0.835 . With adding demographic variables to the model, there were no changes in the inclusion probabilities of samples in the latent class model.

In the latent class regression model with the first class as the reference group, the second class as the response variable, and demographic variables as the predictor variables, it was shown that the education level is the only significant variable that was entered into the model. Also, with increasing the level of this variable, the odds ratio of samples to be in latent class 2 increased by 0.77 .

Different factors can affect the life skills of students. Some of these factors, which are the most important ones, were investigated using an advanced statistical method. However, some other factors such as education discipline, education of parents, race, socioeconomic status, etc. have effects on the life skills of the students while they were not investigated by the authors due to the limitation of sample size. It is suggested that future studies assess the role of these variables in students' life skills. Also, due to differences in different parts of the country, The authors suggest conducting similar studies in different regions of the country.

Using the results of this study, university decisionmakers can identify students with low life skills to increase their skills using educational workshops, lectures, and life skill seminars with suitable planning.

\subsection{Conclusions}

In all subscales of life skills, more than $86 \%$ of the students were classified as highly skilled. The entropy (0.807) for the two-class model revealed that the evaluated classification was good. Moreover, $76 \%$ of the sample units included in the high life skills class had a high probability (95\%). Also, using logistic regression with class 1 as the reference group, it was shown that with an increase in the unit of education level, the chance of including the predictors to be in class 2 increased by 1.77 .

\section{Acknowledgments}

This study was funded by the Deputy of Research of Iran University of Medical Sciences with a reference number of 29485 in 2017. The authors appreciate the University for funding the study and valuable assistance.

\section{Footnotes}

Authors' Contribution: Study concept and data collection: Tofigh Mobaderi; data analysis: Masoud Salehi; cooperation in data analysis and writing the paper: Masoud Roudbari.

Conflict of Interests: The authors have no conflict of interest. 
Ethical Approval: The study was confirmed by the Ethics Council of IUMS under the reference number of IR-IUMSREC-95-03-27-29485.

Funding/Support: This study was funded by the Deputy of Research of Iran University of Medical Sciences with a reference number of 29485 in 2017.

\section{References}

1. Steptoe A, Wardle J. Life skills, wealth, health, and wellbeing in later life. Proc Natl Acad Sci USA. 2017;114(17):4354-9. doi: 10.1073/pnas.1616011114. [PubMed: 28396407]. [PubMed Central: PMC5410802].

2. Jamali S, Sabokdast S, Sharif Nia H, Goudarzian AH, Beik S, Allen KA. The effect of life skills training on mental health of Iranian Middle School students: A preliminary study. Iran J Psychiatry. 2016;11(4):26972. [PubMed: 28050189]. [PubMed Central: PMC5206331].

3. Akhavan Rezayat A, Niroumand S, Shiehzadeh E, Saghebi A, Oskooie RR, Dadgarmoghaddam M. Assessment of life skills of medical students in Mashhad, Iran, in 2015. Electron Physician. 2017;9(10):553640. doi: 10.19082/5536. [PubMed: 29238495]. [PubMed Central: PMC5718859].

4. Harsh VS, Manju G. Strategies for development of life skills and global competencies. Int J Sci Res. 2015;4(6):760-3.

5. Sahebalzamani M, Farahani H, Feizi F. Efficacy of life skills training on general health in students. Iran J Nurs Midwifery Res. 2012;17(7):553-5. [PubMed: 23922605]. [PubMed Central: PMC3730462].

6. Ndetei DM, Mutiso V, Gitonga I, Agudile E, Tele A, Birech L, et al. World Health Organization life-skills training is efficacious in reducing youth self-report scores in primary school going children in Kenya. Early Interv Psychiatry. 2019;13(5):1146-54. doi: 10.1111/eip.12745. [PubMed: 30277311]

7. Wingenbach GJ, Kahler AA. Self-perceived youth leadership and life skills Of Iowa FFA members. J Agr Educ. 1997;38(3):18-27. doi: 10.5032/jae.1997.03018.

8. Lolaty HA, Ghahari S, Tirgari A, Fard JH. The effect of life skills training on emotional intelligence of the Medical Sciences students in Iran.
Indian J Psychol Med. 2012;34(4):350-4. doi: 10.4103/0253-7176.108217. [PubMed: 23723543]. [PubMed Central: PMC3662132].

9. Larsen FB, Pedersen MH, Friis K, Glumer C, Lasgaard M. A latent class analysis of multimorbidity and the relationship to sociodemographic factors and health-related quality of life. A national population-based study of 162,283 Danish adults. PLoS One. 2017;12(1) e0169426. doi: 10.1371/journal.pone.0169426. [PubMed: 28056050]. [PubMed Central: PMC5215832].

10. Liu Z, Zhang Y, Tian L, Sun B, Chang Q, Zhao Y. Application of latent class analysis in assessing the competency of physicians in China. BMC Med Educ. 2017;17(1):208. doi: 10.1186/s12909-017-1039-4. [PubMed: 29132410]. [PubMed Central: PMC5683211].

11. Zhang Z, Abarda A, Contractor AA, Wang J, Dayton CM. Exploring heterogeneity in clinical trials with latent class analysis. Ann Trans Med. 2018;6(7):119. doi: 10.21037/atm.2018.01.24. [PubMed: 29955579]. [PubMed Central: PMC6015948].

12. Harel $\mathrm{O}$, Chung $\mathrm{H}$, Miglioretti $\mathrm{D}$. Latent class regression: Inference and estimation with two-stage multiple imputation. Biom J 2013;55(4):541-53. doi: 10.1002/bimj.201200020. [PubMed: 23712802]. [PubMed Central: PMC3791520].

13. Cogo-Moreira H, Carvalho CA, de Souza Batista Kida A, de Avila CR, Salum GA, Moriyama TS, et al. Latent class analysis of reading, decoding, and writing performance using the Academic Performance Test: Concurrent and discriminating validity. Neuropsychiatr Dis Treat. 2013;9:1175-85. doi: 10.2147/NDT.S45785. [PubMed: 23983466]. [PubMed Central: PMC3748054].

14. Lo Y, Mendell NR, Rubin DB. Testing the number of components in a normal mixture. Biometrika. 2001;88(3):767-78. doi 10.1093/biomet/88.3.767.

15. McLachlan G, Peel D. Finite mixture models. New York: John Wiley \& Sons; 2000. doi: 10.1002/0471721182.

16. Tuttle J, Campbell-Heider N, David TM. Positive adolescent life skills training for high-risk teens: Results of a group intervention study. J Pediatr Health Care. 2006;20(3):184-91. doi: 10.1016/j.pedhc.2005.10.011. [PubMed: 16675379]. [PubMed Central: PMC3074485].

17. Bolsoni-Silva AT, Loureiro SR. Social kills of undergraduates without mental disorders: Academic and socio-demographic variables. PsicoUSF. 2015;20(3):447-59. doi: 10.1590/1413-82712015200307. 